\title{
Business Simulation Training in Information Technology Education: Guidelines for New Approaches in IT Training
}

\author{
Pierre-Majorique Léger \\ HEC Montréal, Montréal, Canada \\ pml@hec.ca
}

\author{
Patrick Charland \\ Université du Québec à Montréal \\ (UQAM), Canada \\ charland.patrick@uqam.ca \\ Jacques Robert \\ HEC Montréal, Montréal, Canada \\ Jacques.Robert@hec.ca
}

hfeldstein@batonsimulations.com

Gilbert Babin

HEC Montréal, Montréal, Canada

gilbert.babin@hec.ca

\author{
Derick Lyle \\ HEC Montréal, Montréal, Canada \\ Derick.Lyle@hec.ca
}

\section{Executive Summary}

Enterprise Resource Planning (ERP) systems are commercial software packages that enable the integration of transactions-oriented data and business processes throughout an organization. Most of the world's largest organizations have already adopted an ERP system, and many mid-size organizations are turning to them as well. The implementation of an ERP system presents some major training challenges. Organizations devote significant portions of their implementation budgets to training and organizational change management interventions. Industry experts recommend that up to $20 \%$ of an implementation budget be devoted to adequately preparing managers and users. Studies also show a low return on investment for this type of training as it makes it difficult for knowledge workers to teach how to transfer what is learned in training to real-life jobs. Inadequate and ineffective training has the potential to seriously limit value realization. In that context, this paper presents ERPsim, a business simulation training approach developed at HEC Montréal in which the only interface between participants and the game is a real-life enterprise system (SAP). ERPsim recreates a realistic business environment that allows learners to develop IT competencies and skills in a setting that reflects the true complexity of the business world. This simu-

Material published as part of this publication, either on-line or in print, is copyrighted by the Informing Science Institute. Permission to make digital or paper copy of part or all of these works for personal or classroom use is granted without fee provided that the copies are not made or distributed for profit or commercial advantage AND that copies 1) bear this notice in full and 2) give the full citation on the first page. It is permissible to abstract these works so long as credit is given. To copy in all other cases or to republish or to post on a server or to redistribute to lists requires specific permission and payment of a fee. Contact Publisher@InformingScience.org to request redistribution permission. lation approach is now used in over 100 universities and a dozen Fortune 1000 organizations. Yet, our experience shows that trainers need to approach simulation game training with a different attitude. This paper addresses the challenges faced by IT trainers in adapting to this innovative training approach. Based on our many training experiences, this paper provides instructors with guidelines to create a learning environ- 
ment where learners have a reduced risk of making mistakes, to provide scaffolds that help learners build self confidence, and to help learners reflect on their mistakes, speculate on root causes, and intelligently design alternative solutions. Instructors trained with this approach report significant improvements in student evaluation, learner motivation, attendance, and engagement as well as increased learner competence with the technology. These guidelines can be transferred to a variety of other educational fields in which trainers are migrating towards a more active educational approach.

Keywords: Simulation game, Problem-based learning, Instructional strategy, ERP systems.

\section{Introduction}

In the current global economy, firms must innovate in order to stimulate growth and remain competitive. Enterprise systems play a crucial role in the growth of productivity and increasing business competitiveness. Enterprise Resource Planning (ERP) systems are commercial software packages that enable the integration of transactions-oriented data and business processes throughout an organization (Markus \& Tanis, 2000).

The need to teach future business graduates the challenges and impact of these integrated systems has been stressed in both professional and academic literature (Hawking, McCarthy, \& Stein, 2004; Peslak, 2005; Seethamraju, 2007). Training IT professionals on these systems is usually done with a traditional instructional approach accompanied with hand-on exercises using fictional cases on a dedicated training system (Yi \& Davis, 2003). Users in this type of training are engaged in an individual cognitive process that mostly leads to knowledge acquisition of the applications (Kang \& Santhanam, 2003-2004). Traditional training does not address the intrinsic complexity of the real-life business situations required to build professional IT competency (Basselier, Horner Reich, \& Benbasat, 2001). Furthermore, traditional teaching does not facilitate interindividual learning. Specifically, in an integrated application, the challenge is how to adequately train users to effectively coordinate their interactions with other system users (Sharma \& Yetton, 2007).

In recent years, many education programs have turned to a more experiential-based training approach relying on situated cognition theory (J. S. Brown, Collins, \& Duguid, 1989; Herrington \& Oliver, 2000) and problem-based learning (Hmelo-Silver, Duncan, \& Chinn, 2007). Yet, one obstacle in adopting these new educational methods has been the training of faculty members and instructors on how to develop and use this approach in the classroom. Education professionals are no exception. Teaching methodologies that have proven effective in traditional models may be inefficient in experiential interventions.

This paper presents ERPsim, an innovative training environment and approach developed at HEC Montréal to address the challenges in learning to use and understand ERP systems (Léger, 2006; Léger, Robert, Babin, Pellerin, \& Wagner, 2007). This simulation game has been used in more than 750 sessions around the world, both in academia and in real companies. The result of 6 years of experience in training instructors and faculty members to use ERPsim in the classroom, this paper raises issues and proposes guidelines for training trainers in new educational approaches, such as the ERPsim business simulation game. These guidelines are focused on active learning and team problem solving and can be applied to various IT courses.

\section{Trends in Higher Education: From Situational Theory to Simulation Games}

With a growing emphasis on contributing to graduate employability, more and more training programs foster the implementation of better student-centered and competency driven programs 
(Andriole, 2006; Strata-Etan, 2003) . Researchers in education suggest that situational cognition and problem-based learning might provide instructional strategies that are better aligned with the challenges underlying IT competency development (A. L. Brown, 1992; Lave, 1988).

Situated cognition theory states that activities, tasks, and understanding do not exist in isolation, but rather are part of broader relationship systems. Learning thus implies addressing the possibilities enabled by these relationship systems (Lave \& Wenger, 1991). According to Kumar (1996), there are many advantages to the situated cognition approach. Firstly, by linking specific contexts and knowledge together, learners can understand under which conditions knowledge should be applied. These learners can then understand how their knowledge can be applied or transferred to new situations. Collins, Brown, and Newman (1989) argue that learning in multiple contexts induces the abstraction of knowledge so that students acquire knowledge in a dual form, both tied to the contexts of its uses and independent of any particular context. This unbinding of knowledge from a specific context fosters its transfer to new complex problems and domains. Research suggests that situated cognition is associated with a higher level of engagement and motivation in learners and generally leads to a better understanding and transfer of knowledge.

Immersive instructional strategies such as simulation-based learning enable situated cognition learning through the recreation of real world problem-solving situations. Simulations are goaloriented and structured to lead learners towards the desired learning outcome. They also involve interaction that allows learners to test problem-solving strategies, experience the consequences of their actions, and adjust their decisions in a safe environment. Well designed simulation learning experiences are generally associated with accelerated competency development and deeper understanding (O’Neil, Wainess, \& Baker, 2005; Randel, Morris, Wetzel, \& Whitehill, 1992). Reeves (1993) considers the ability to include "opportunities for simulated apprenticeships as well as a wealth of learning support activities" to be one of the major benefits of a well designed multimedia environment. Many researchers and teachers exploring the model of situated learning have accepted that computers can provide an alternative to real-life settings and that technology can be used without sacrificing the authenticity so critical to the model. McLellan (1994) summarized these approaches by pointing out that, while knowledge must be learned in a context suited to the situated learning model, "context can be the actual work setting, a highly realistic or "virtual' surrogate of the actual work environment, or an anchoring context such as a video or multimedia program" (p. 8).

The use of games, simulations, and case-based models is a well-established paradigm for teaching business skills (Schrage, 2000). Beginning with the Harvard Business School case model, through the Beer Game developed by the systems dynamics group at MIT in the early 1960s, simulation is recognized as one of the most effective ways of teaching higher order skills (analysis, synthesis, creation of new knowledge and categories, discerning value). There is little empirical evidence proving or disproving these claimed benefits (e.g., see Stolovitch \& Yapi, 1997), but there is a lively scholarly debate on the issue.

A possible explanation for the little evidence found is that most simulations in IT lack contextual realism. Learners are asked to solve problems and make decisions in a milieu that is far removed from the real business world where corporate information systems are needed to tackle complex decision making under rapidly changing conditions. Therefore, the main challenge is recreating realistic business environments and having participants use real-life IT artifacts to solve complex business problems.

\section{ERPsim: A Simulation Game for Teaching ERP Concepts}

ERPsim was developed at HEC Montréal by a team of multidisciplinary faculty members and collaborators. This team created a series of business simulation games in which teams of partici- 
pants operate a company using an ERP system. ERPsim is a unique business simulation technology that enables the simulation of near-real-life business contexts in large corporate information systems. The ERPsim Administrator Console is shown in Figure 1.

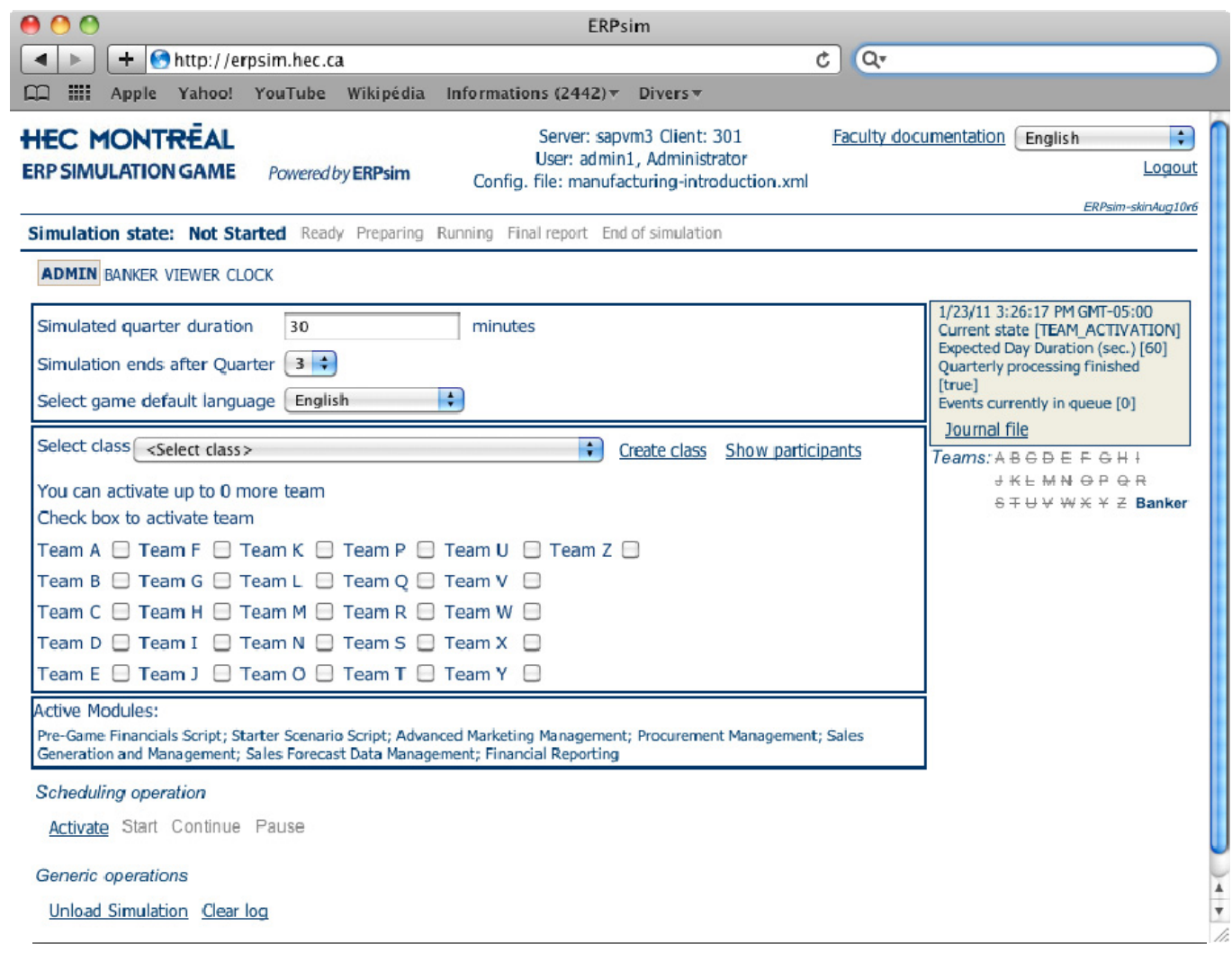

Figure 1. ERPsim Administrator Console

The different simulation games have two features that distinguish them from traditional business games. First, the HEC Montréal ERP simulation games are run in real-time. Instead of having one or two hour rounds, the simulator reacts almost instantly to teams' decisions. Every minute the simulator picks up any changes and decisions made by participants and provides an immediate response from the simulated market. In this context, teams can quickly detect and correct errors within minutes. They learn how to use instant feedback from the simulated marketplace to adapt and revise their decisions.

The second and essential feature of these simulation games is that the only interface between the simulator and the participants is a real ERP system, namely SAP ERP (ECC 6.0). All decisions made by participants must be entered into the system, and all information about the evolution of the game is retrieved from a standard or customized system. Hence, participants are put in a situation in which they have to run their business (making and implementing business decisions) using a SAP system similar to those used by the world's largest companies. This creates a unique learning environment where participants can experience the value of an integrated business system hands-on.

The pedagogical objectives for this game are fourfold. First, ERPsim aims to develop hands-on understanding of the concepts underlying enterprise systems. Second, the simulation game allows students to experience the benefits of enterprise integration firsthand. Third, by navigating and 
making decisions in a real ERP system, students develop technical ERP system skills. Finally, students learn how to create, execute, and adapt a business strategy in a real-time environment. Evidence of the benefits of this simulation game based approach to teaching ERP concepts has been reported by several researchers (Cronan, Douglas, Schmidt, \& Alnuaimi, 2009, 2009b; Freeze, Lane, \& Sasidharan, 2010; Konstantinidis \& Kienegger, 2010; Kreie \& Mora-Mongel, 2010; Kreie \& Shannon, 2010; Léger et al., 2010; Pittarese, 2009; Seethamraju, 2008).

Two main business simulations have been created using the ERPsim environment. One is built around a make-to-stock manufacturing company where participants must operate the full business cycle (plan, procure, produce, and sell). The second is built around a distribution company. In each of these simulations, participants run a company in a simulated economic environment in teams of 2 to 5 players. Specifically, participants must operate the full business cycle of their organization; they must plan, procure, produce, and sell. Students must use the ERP system to:

1. Forecast sales and plan production

2. Calculate the material requirement

3. Manage stock

4. Schedule production

5. Manage sales

6. Execute other administration functions such as accounting and finance

The Figure 2 illustrates the scope of the manufacturing simulation game. Shaded rectangles represent SAP transactions automated by ERPsim, while other transactions are those students must perform to manage their company.

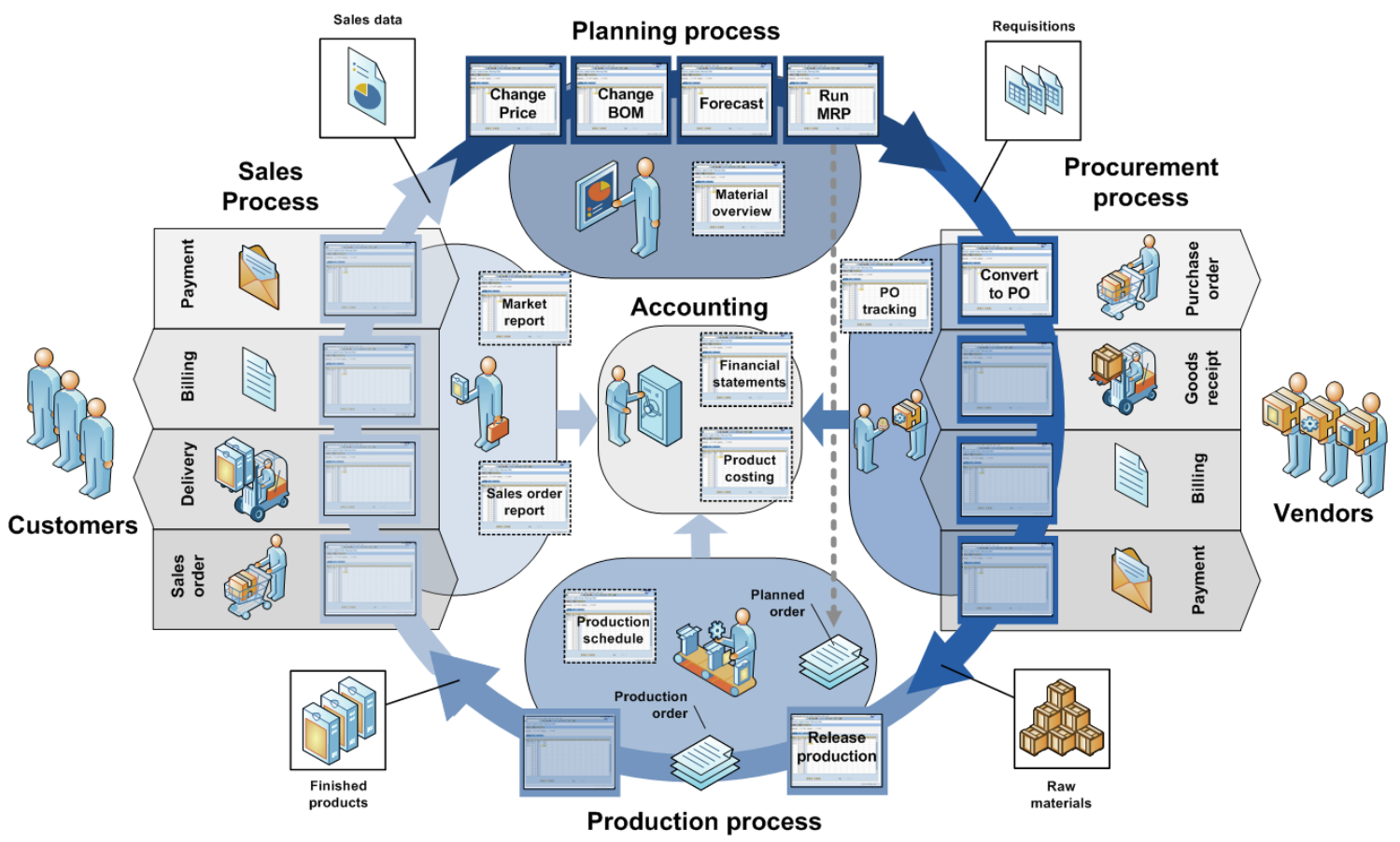

Reproduced with the authorization of Léger et al 2010, ERP Simulation Game: Participant's Guide, ERPsim Lab, Montréal.

Figure 2 Scope of the Manufacturing Simulation Game 
These simulation games are designed to let the learner experience the value of up- and downstream information flows through this real world system and process integration across functional silos, so that they can understand how not making a decision in time or making a poor decision can impact the follow-on of a business cycle. These games were also designed to provide a rich and economically representative simulation of a medium-sized organization. Specifically, the simulations were endowed with a rich and realistic demand model, constraints and delays in the supply chain, and liquidity and warehousing constrains. These constraints force participants to make important strategic choices and to use the system efficiently if they wish to achieve operational excellence. By experiencing the simulation, participants get to understand what it takes to operate real companies using an integrated system, as opposed to a simulated environment that only focuses on strategy.

Figure 3 presents a typical ERP course curriculum using the different simulation games over a 6 week period (half a semester in most AACSB colleges and universities.) In the first class students are introduced to the ERP system by playing the distribution game, in which they play 3 simulation rounds of 20 minutes each. Between the rounds and during the final debriefing students discuss the value of an ERP system and are able to define the main properties and benefits of this type of business application. In classes 2 and 3 students are introduced to a more difficult business environment: a manufacturing company. Using a back-chaining model, they first learn to manage the sales process, to control the production of the new product, to perform the planning process, and finally to execute the procurement process. In classes 4 and 5 the complexity of the simulation increases and students have to take new financial and operational constraints into account. They also need to use reporting and analytical tools available in the ERP system to improve their decision making capability. During class 6 , students must apply what they learned in a final simulation game. After the game, participants are debriefed on the simulation results by explaining how they used the ERP system to manage their organization. It should be noted that curriculums vary from one faculty to another. Some choose to use the distribution game in the introduction to MIS course, while others only focus on the introductory manufacturing game.

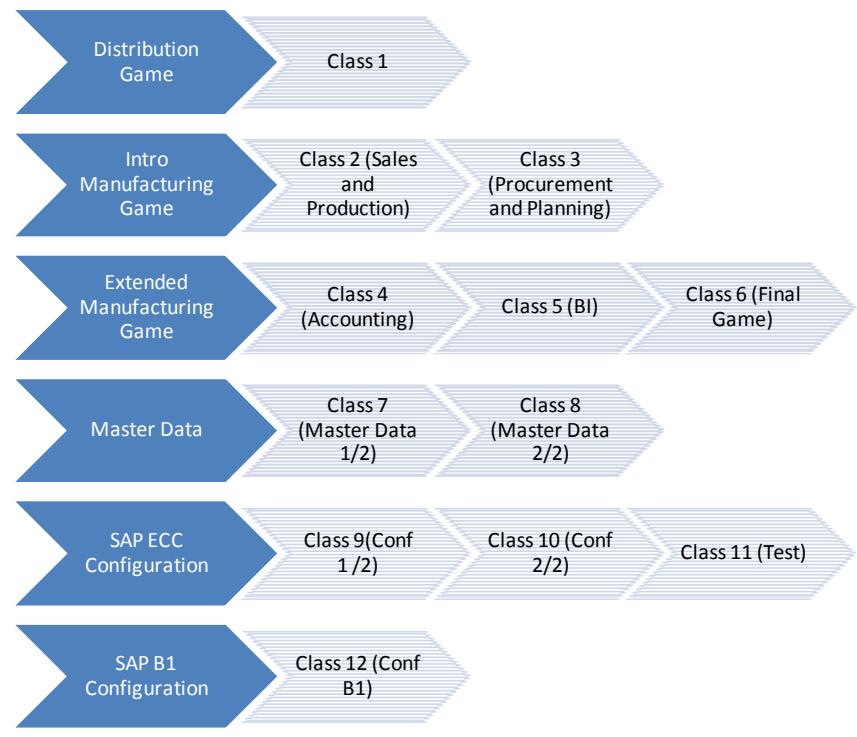

Figure 3 Typical Curriculum Using Multiple ERPsim Games 
In the academic world, the ERPsim software and access to an SAP system are provided through the SAP University Alliance (SAP UA). "The SAP University Alliances program is a global endeavor that provides university faculty members with the tools and resources necessary to teach students how technology can enable integrated business processes and strategic thinking" (SAP University Alliances, n.d.). Through the SAP UA, universities and colleges can gain access to the SAP Business Suite; HEC Montreal has granted a free license to use ERPsim within the University Alliance.

\section{Elements of Method}

Over the past six years, the ERPsim Development Team has trained over 300 instructors worldwide to use simulation games to teach ERP concepts to IT professionals. These instructors are faculty members and instructors at universities and colleges, teaching ERP systems in fields such as Management Information System, Computer Science, Operations Management, and Industrial Engineering. So far, ERPsim has been used in more than 130 universities worldwide. We have also trained 49 certified faculty members who are allowed to train other instructors. Overall, more than 38 instructor training sessions were organized worldwide to train new instructors on ERPsim. At the end of each instructor training, we summarized the questions received during the training and the comments received during the debriefings. Following guidelines suggested by Glasser and Strauss (1967), a qualitative approach was used to classify and group the ideas presented in the next section.

Between September 2009 and November 2010, more than 750 simulations games (540 distribution games and 210 manufacturing games) were played by several thousand university and college students. (Statistics are not available before 2009.) A portal (http://erpsim.hec.ca/learning) was created in August 2009 to make our pedagogical material available to faculty and students, and so far 9,300 unique visitors from 38 countries have accessed this learning portal. Questions, comments, and suggestions about ERPsim teaching practices in were also analyzed.

We also examined "our" own teaching practices in training IT students (bachelor/MBA) in over 100 simulations during the last six years. Based on this experience, we have drawn a list of observations that we believe are essential factors in successfully teaching ERP concepts using a simulation game.

\section{Learning to Teach IT Differently}

This section describes the main observations induced from our experience in running training session for professors, lecturers, and professional trainers since the creation of the project. These observations are presented herein. We believe that they constitute a set of guidelines that should be followed by instructors using the simulation game with adult learners.

\section{Becoming Coaches}

One of the first comments made by faculty members trained to use a simulation game in IT is that they realize they have to adopt a less intrusive role in the student learning process. Traditional IT training often relies on linear and detailed intensive transactional knowledge acquisition. In such training, the instructor will generally have a very active role in the learning process. Instructors are likely to perform live demonstration followed by hands-on examples by participants.

In the simulation game, instructors must learn to become coaches (Bolton, 1999; Harley, 1993). Using a problem-solving based approach, learners are put in a situation where they must find the appropriate transaction knowledge required to complete their task. As coaches, trainers must give minimum information in order to make sure learners can complete the task with a certain level of challenge. Using appropriate knowledge, tools, and methodology, learners identify the options 
available and choose the right course of action in the system. In the early stages of a simulation game, learners are likely to seek technical advice, whereas as the game progresses learners will want more tactical advice on how to use the information system to achieve their organizational goals. Coaching participants will generally involve reviewing managerial and information system concepts with learners to help them find solutions to technical and business issues their company encounters in the game.

\section{Making It Safe for Students to Experiment}

This leads to our second observation. In the simulation game context, we observed that the participants' primary learning is not related to system transactional knowledge. The objective is to make learners independent as quickly as possible and establish a learning environment where people feel really safe to try things, to experiment, and to fail. In a certain way, this is a learning context where we are actually celebrating failure rather than penalizing failure (Burleson, Picard, Perlin, \& Lippincott, 2004; Schank \& Neaman, 2001).

By making it safe to fail, learners are able to try and experiment. Through trials and errors, learners will eventually be able to induce a set of guiding principles. Creating a "safe place for experimentation and failure" in a university setting may take many forms. One way is for the instructor to model the right approach to "failure" and not knowing: i.e., by expressing curiosity with things that do not go quite right, by admitting that many things are unknown (even by the instructor), and by teaching that when things turn out unexpectedly it is an invitation for open investigation.

Over the many times we used the simulation, we realized that to create an environment where participants develop a natural inclination to try and discover, coaches must not be seen as the main knowledge providers. The main idea is to give just enough information so learners can start exploring on their own. In others words, participants are given a scaffold on which they can rely, eliminating the need for continuous instructor help: similar to how parents provide many "scaffolds" for toddlers learning to walk. More specifically, scaffolding is the process of providing learners with the assistance needed to solve problems that would otherwise be too difficult (Collins et al., 1989; Vygostki, 1978). In an educational context, scaffolding should not only help learners complete a task, but also ensure that they learn from the experience (Reiser 2004).

In the ERPsim world, scaffolding comes in the form of a well designed job aid that students can refer to in order to get a job done quickly and simply. Additional documentation building on Black, Carroll, and McGuigan (1987) is available but follows the "minimal instruction" approach. This is obviously quite different than the traditional IT learning methodology where students generally receive heavy technical binders at the start of a workshop, and then have to master and memorize their content and take extensive notes to learn everything about the software. It should be noted that this traditional approach may have a role in advanced technical courses. But in order to introduce management students to the concepts of integration and holistic visibility in an enterprise system, too much information is likely to cause the learner to lose sight of the forest for the trees.

While participants need good initial documentation, this support should certainly not answer all their questions. Our experience is that a single sheet of technical information is usually enough to get people started and confident in using the application. Learning takes place as people actually engage in the simulation and find solutions by themselves to problems they encounter. The initial documentation gives participants a scaffold, a framework in which they can work.

Making participants realize that they failed is one of the critical success factors for running an IT simulation game that we have identified through our many experiences. It is actually part of the learning process. Supporting people as they fail is the key to having them develop the confidence 
required to try again. When teaching a baby to walk, parents often provide a lot of support, particularly when the baby has problems. Parents offer verbal and physical support and will generally offer some form of scaffolding as an option. They are supporting the inevitable failures that must happen: all children fall down many times before mastering the myriad of skills required to walk with fluency and ease.

Therefore, at the beginning of the simulation game when participants ask questions, answers must be provided to them in a clear and precise way. But, as the simulation game goes on, scaffolding must fade and be removed (Reiser, 2004). When questions from learners arise at this point, answers should be about helping them to generate alternatives or identify the source of the problem. The instructor could say, "Well, that is a really good question." "How would you find that out?" "What could the answer be?" "Can you speculate on why this might have happened?" That is the fading or the removing of the scaffolding.

\section{Learning to Detect and Correct Errors}

We also observed that participants do not learn only by failing. If we fail a thousand times but do not understand the reasons behind the failures and adjust our behavior accordingly, we will never learn. There is an intervening process required for the learning to occur. This is referred to this as the detection and correction of an error.

Participants in a serious game must try something, even though they may not have complete or clear information about the best course of action. Inevitably, they will experience some degree of

failure. The failure sets the stage for inquiry, analysis, and synthesis and leads to the re-shaping of understanding and strategy. For example, this can simply be at the transactional level in the information system, or even at the key stroke level: "I pressed the wrong key and I must figure out how to reverse my actions." It could be at the process level: "I tried this tactical action, it didn't give the expected result. I need to try something else." Participants may find that by trying lots of things they start to understand the systemic relationships within the software. They also may discover more effective heuristics for deciding what to try next. By examining failures, and reflecting on larger causal issues, including their own assumptions about the system, they may discover new patterns that can inform their approach to subsequent failures.

In traditional IT training, instructors are likely to intervene to prevent "falling." If they see someone going down the wrong path, they want to help the student avoid the wasted time and frustration of failure. In a simulation, it may be far more helpful to allow the error to occur and then coach through the process of detection and correction. "This is a very interesting error." "Can you find out how you made that error?" "Can you do analyze why that error happened?" "What assumptions are you making that might not be accurate?" "How might these assumptions actually prevent you from seeing alternative ways of understanding and acting?"

\section{Exploration vs. Exploitation}

Participants in a game begin with very little information about the economic environment in which their team and the others are competing. Crucial decisions such as pricing, advertising investment, and the selection of products to focus on, require minimum information. Information is provided about the cost of goods (initial prices in the system) and we provide a rough idea of the market size. Otherwise, participants are to learn about the market condition over the course of the game.

Beyond learning how to use the IT system, teams must also learn about the economic conditions of the game. They must learn to become a learning organization. We invite teams to find the right tradeoff between exploration and exploitation. Exploration involves trying new things, accepting that one cannot be right the first time, testing new strategies and measuring their success. Exploi- 
tation involves using a proven and tested strategy. Hence, we encourage participants to use exploration in the first stage (introductory game) and exploit what they have learned in later rounds.

\section{Multidisciplinary Knowledge}

One of the most challenging elements we observed in running the simulation is that in order for professors and instructors to teach such a course, they require extensive knowledge on various business concepts. It might seem unintuitive, but it appears that the technical knowledge is often the easiest part when it comes to understanding the underlying principles of an ERP system in this simulation game context. The most difficult piece of knowledge is often related to the understanding of the business context and management of the simulation companies. Because our simulation design makes no attempt to fragment or simplify real-life business contexts (Honebein, Duffy, \& Fishman, 1993; Spiro, Vispoel, Schmitz, Samaxapungavan, \& Boeger, 1987; Young \& McNeese, 1993) trainers have to deal with the complexity of an authentic business. Professors and lecturers in Information System Management may have educational backgrounds in business, but their knowledge of accounting and operations management is not likely to be at the core of their expertise.

Because participants in a simulation game are driven by the motivation of winning the game and, therefore, making the most profit possible, participants tend to be very interested in understanding all cost drivers that impact their final results. Participants also rapidly understand how important some operations management concepts are to operating a lean operation, and how important a good understanding of the material requirement planning (MRP) concepts can be in the game. As a coach, the trainer must be able to master these non-MIS concepts because as the game progresses, participants are less likely to ask on which button to click and are more likely to wonder how ERP systems can help them reduce their operating costs and better handle a just-in-time manufacturing operation. Therefore, we found that we must invest a large part of our instructor training to reviewing these concepts in order for trainers to be more effective at using the simulation game.

\section{Debriefing and Instructing}

Our experience has demonstrated that at the end of the simulation, debriefing is a necessary step to "crystallize" or, as they say in education research, to "integrate" the learning that occurred during the experiential event. Thiagarajan and Stolovitch (1978) stress that "debriefing enables the players to think back on their experience, vent their feelings and relate the game to the reality it represents" (p.45). For Riis, Johansen, and Mikkelsen (1995), the debriefing stage serves to examine the simulation game, discuss the results, and turn the experience into learning. Without a good debriefing, students who might not have had the best performance in the simulation might leave with the wrong take-home message. In our experience, we found that participants must reflect on the whole experience of the simulation and not just the result (either positive or negative). This means directing the discussion away from the things students most want to talk about (here's what we did) and toward higher order observations: "What kinds of team behaviors help or hinder?"; "How important is role clarity?"; "Was your team able to make full use of all team members' intelligence, or were some people under-used?"; "What is required to get full use of everyone's intelligence?"; "What is required for a team to get maximum value from an ERP system?"; "What is a silo?"; "Did one emerge in the game?"; "What is the effect of a silo?". During these debriefings we stress the fact that a team that did not have the best results in the game but that is able to explain the source of their problems is better off than a team that did well in the game but does not clearly understand how they succeeded.

Our experience also shows that having a more formal teaching presentation prepared can be useful for the debriefing. This is a good opportunity to review some of the main concepts behind in- 
tegration and decision support systems and to provide definitions and characteristics. With the simulation game experience, learners are likely to better relate to these definitions now that they have used the system in a quasi-real setting. A traditional approach to debriefing can help crystallize learning that occurred during the experiential events. This often brings a new perspective for direct instructions which are now linked to meaningful problems that students just encountered. In other words, students are able to appreciate the meaningfulness of the formal knowledge required to perform well in the simulation.

\section{Concluding Remarks}

Using problem-based learning and simulation-based approaches to teaching IT requires new instructional strategies to fully leverage their pedagogical benefits. In fact, it is likely that using these approaches without the right teaching perspective could lead to a pedagogical context that may hinder the learner in acquiring the expected knowledge and competencies. The objective of this paper was to summarize the observations we made in training hundreds of faculty members in using a simulation to teach the concepts underlying ERP systems. It should be noted that these observations are congruent with previous findings related to the use of simulation games in business administration (Anderson \& Lawton, 2009; Schrage, 2000). The main contribution of this paper is to draw attention to the pedagogical strategy required to engage students in a context where learning the IT artifact is fun and risk-free.

We are currently in the process of preparing a pedagogical book for IT faculty members to assimilate these guidelines into their practice. The teaching notes will include practical implementation of these guidelines. It should be noted that the guidelines identified in this paper could be transferred to many other educational fields where trainers are heading towards the problembased learning paradigm.

\section{References}

Anderson, P., \& Lawton, L. (2009). Business simulations and cognitive learning: Developments, desires, and future directions. Simulation \& Gaming, 40(2), 193-216.

Andriole, S. J. (2006). Business technology education in the early $21^{\text {st }}$ century: The ongoing quest for relevance. Journal of Information Technology Education, 5, 1-12. Retrieved from http://www.jite.org/documents/Vol5/v5p001-012Andriole36.pdf

Basselier, G., Horner Reich, B., \& Benbasat, I. (2001). Information technology competence of business manager: A definition and research model. Journal of Management Information Systems, 17(4), 159182.

Black, J., Carroll, J., \& McGuigan, S. (1987). What kind of minimal instruction manual is the most effective? Proceedings of CHI, 159-162.

Bolton, M. K. (1999). The role of coaching in student teams: A "just-in-time" approach to learning. Journal of Management Education, 23, 233-250.

Brown, A. L. (1992). Design experiments: Theoretical and methodological challenges in creating in complex interventions in classroom settings. Journal of the Learning Sciences, 2(2), 141-178.

Brown, J. S., Collins, A., \& Duguid, S. (1989). Situated cognition and the culture of learning. Educational Researcher, 18(1), 32-42.

Burleson, W., Picard, R. W., Perlin, K., \& Lippincott, J. (2004). A platform for affective agent research. Workshop on Empathetic Agents, International Conference on Autonomous Agents and Multiagent Systems, Columbia University, New York, NY, USA. 
Collins, A., Brown, J. S., \& Newman, S. E. (1989). Cognitive apprenticeship: Teaching the crafts of reading, writing, and mathematics. In L. B. Resnick (Ed.), Knowing, learning, and instruction: Essays in honor of Robert Glaser (pp. 453-494). Hillsdale, NJ: Lawrence Erlbaum Associates.

Cronan, T. P., Douglas, D. E., Schmidt, P., \& Alnuaimi, O. (2009a). ERP simulation game; Learning and attitudes toward SAP samples company 'First Time Hires'. ITRI-WP123-1009, Information Technology Research Institute, University of Arkansas.

Cronan, T. P., Douglas, D. E., Schmidt, P., \& Alnuaimi, O. (2009b). Evaluating the impact of an ERP simulation game on student knowledge, skills, and attitudes. ITRI-WP123-1008, Information Technology Research Institute, University of Arkansas.

Freeze, R., Lane, P., \& Sasidharan, S. (2010). Expert relativity: Identify the expert just ahead. Proceedings of AMCIS 2010, Paper 397.

Glaser, B. G., \& Strauss, A. L. (1967). The discovery of grounded theory: Strategies for qualitative research. Chicago: Aldine Publishing Company.

Harley, S. (1993). Situated learning and classroom instruction. Educational Technology, 33(3), 46-51.

Hawking, P., McCarthy, B., \& Stein, A. (2004). Second wave ERP education. Journal of Information Systems Education, 15(3), 327-332.

Herrington, J., \& Oliver, R. (2000). An instructional design framework for authentic learning environments. Educational Technology Research and Development, 48(3), 23-48.

Hmelo-Silver, C. E., Duncan, R. G., \& Chinn, C. A. (2007). Scaffolding and achievement in problem-based and inquiry learning: A response to Kirschner, Sweller, and Clark. Educational Psychologist, 42(2), 99-107.

Honebein, P. C., Duffy, T. M., \& Fishman, B. J. (1993). Constructivism and the design of learning environments: Context and authentic activities for learning. In T. M. Duffy, J. Lowyck, \& D. H. Jonassen (Eds.), Designing environments for constructive learning (pp. 87-108). Heidelberg: Springer-Verlag.

Kang, D., \& Santhanam, R. (2003-2004). A longitudinal field study of training practices in a collaborative application environment. Journal of Management Information Systems, 20(3), 257-281.

Konstantinidis, C., \& Kienegger, H. (2010). Planspiele in der ERP-lehre: Eine empirische untersuchung deutscher bildungseinrich-tungen. Proceedings of the 2010 Multikonferenz Wirtschaftsinformatik, Göttingen, Germany, 1709-1721.

Kreie, J., \& Mora-Monge, C. A. (2010). Going from data to decisions: Preparing students to use enterprise systems. Proceedings of the 2009 ISECON, Washington, DC, USA, 1-7.

Kreie, J., \& Shannon, J. (2010). An enterprise system and a business simulation provide many opportunities for interdisciplinary teaching. Proceedings of the 2010 ISECON, Nashville, TN, USA, 1-8.

Kumar, V. S. (1996). Computer-supported collaborative learning: Issues for research. Retrieved from: University of Saskatchewan, Department of Computer Science Web site:

http://edutechwiki.unige.ch/en/Shared_cognition

Lave, J. (1988). Cognition in practice. Cambridge, UK: Cambridge University Press.

Lave, J., \& Wenger, E. (1991). Situated learning: Legitimate peripheral participation. Cambridge, UK: Cambridge University Press.

Léger, P.-M. (2006). Using a simulation game approach to teach enterprise resource planning concepts. Journal of Information Systems Education, 17(4), 441-447.

Léger, P.-M., Robert, J., Babin, G., Pellerin, R., \& Wagner, B. (2007): ERPsim, ERPsim Lab (erpsim.hec.ca), HEC Montréal, Montréal, Qc.

Léger, P.-M., Charland, P., Pellerin, R., Babin, G., Robert, J., \& Cronan, T. P. (2010). A problem based learning approach to teach operation management in an enterprise system context? Working paper no. 10-06, ERPsim Lab, HEC Montréal. 
Markus, M., \& Tanis, C. (2000). Enterprise systems: From adoption to business value. In R. W. Zmud (Ed.), Framing the domains of IT research: Glimpsing the future through the past. Cincinnati, OH: Pinnaflex Educational Resources.

McLellan, H. (1994). Situated learning: Continuing the conversation. Educational Technology, 34(10), 7-8.

O'Neil, H. F., Wainess, R., \& Baker, E. L. (2005). Classification of learning outcomes: Evidence from the computer games literature. The Curriculum Journal, 16, 455-474.

Peslak, A. R. (2005). A twelve-step, multiple course approach to teaching enterprise resource planning. Journal of Information Systems Education, 16(2), 147-155.

Pittarese, T. (2009). Teaching fundamental business concepts to computer science and information technology students through enterprise resource planning and a simulation game. Journal of Computing Sciences in Colleges, 25(2), 131-137.

Randel, J. M., Morris, B. A., Wetzel, C. D., \& Whitehill, B. V. (1992). The effectiveness of games for educational purposes: A review of the research. Simulation and Gaming, 25, 261-276.

Reiser, B. J. (2004). Scaffolding complex learning: The mechanisms of structuring and problematizing student work. The Journal of the Learning Sciences, 13(3), 273-304.

Reeves, T. C. (1993). Interactive learning systems as mindtools. In P. Newhouse (Ed.), Viewpoints 2 (pp. 211, 29). Perth, Australia: Educational Computing Association of Western Australia.

Riis, J. O., Johansen, J., \& Mikkelsen, H. (1995). Simulation games in production management: An introduction. In J.O. Riis (Ed.), Simulation games and learning in production management (pp. 3-25). London, UK: Chapmann \& Hall.

SAP University Alliances. (n.d.). Retrieved from http://www.sdn.sap.com/irj/uac

Schank, R., \& Neaman, A. (2001). Motivation and failure in educational systems design. In K. Forbus \& P. Feltovich (Eds.), Smart machines in education (pp. 37 - 69). Cambridge MA: AAAI Press/ The MIT Press.

Schrage, M. (2000). Serious play: How the world's best companies simulate to innovate. Boston, MA: Harvard Business School Press.

Seethamraju, R. (2007). Enterprise systems (ES) software in business school curriculum: Evaluation of design and delivery. Journal of Information Systems Education, 18(1), 69-84.

Seethamraju, R. (2008). Enhancing student learning of enterprise integration through ERP business simulation game. Proceedings of the International Conference of the AIS SIGED: IAIM, Paris, France.

Sharma, R., \& Yetton, P. (2007). The contingent effects of training, technical complexity and task interdependence on successful information systems implementation. MIS Quarterly, 31(2), 219-238.

Spiro, R. J., Vispoel, W. P., Schmitz, J. G., Samaxapungavan, A., \& Boeger, A. E. (1987). Knowledge acquisition for application: Cognitive flexibility and transfer in complex content domains. In B. K. Britton \& S. M. Glynn (Eds.), Executive control processes in reading (Vol. 31, pp. 177-199). Hillsdale, NJ: Lawrence Erlbaum Associates.

Stolovitch, H. D., \& Yapi, A. (1997). Use of case study method to increase near and far transfer of learning. Performance Improvement Quarterly, 10(2), 64-82.

Strata-Etan Expert Group. (2003). Higher education and research for the ERA: Current trends and challenges for the near future. Brussels, Belgium: European Commission, DG Recherche.

Thiagarajan, S., \& Stolovitch, H.D. (1978). Instructional simulation games. Englewood Cliffs: Educational Technology.

Vygotsky, L S. (1978). Mind in society: The development of higher psychological processes. Cambridge, MA: Harvard University Press. 
Yi, M. Y., \& Davis, F. D. (2003). Developing and validating an observational learning model of computer software training and skill acquisition. Information Systems Research, 14(2), 146-169.

Young, M. F., \& McNeese, M. (1993). A situated cognition approach to problem solving with implications for computer-based learning and assessment. In G. Salvendy \& M. J. Smith (Eds.), Human-computer interaction: Software and hardware interfaces. New York, NY: Elsevier Science Publishers.

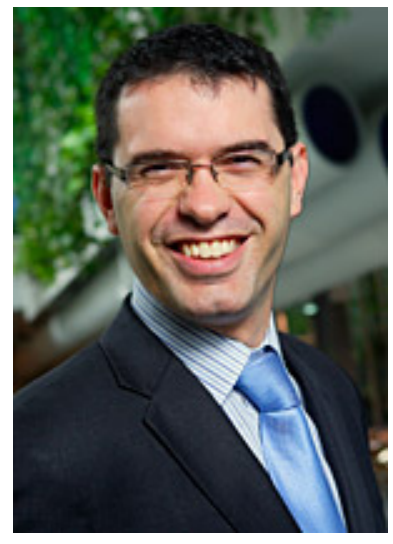

\section{Biographies}

Dr. Pierre-Majorique Léger is an Associate Professor in information technologies at HEC Montréal. He holds a PhD in industrial engineering from École Polytechnique de Montréal and has done post-doctoral studies in information technologies at HEC Montréal and NYU Stern. $\mathrm{He}$ is the Director of ERPsim Lab, an R\&D center in the field of serious games for end-user IT training. He is also co-director of Tech3Lab, a business user experience lab in the field of NeuroIS. He is a co-creator of ERPsim, a simulation game to teach ERP concepts, which is now used in more than 150 universities worldwide and many Fortune 1000 organizations.

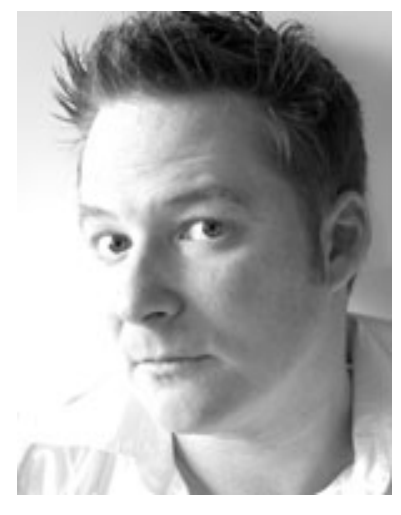

Dr. Patrick Charland is an associate professor in Education and pedagogy Department at Université du Québec à Montréal (UQAM). His researches focus on general educational reform tendencies. He studies teaching, training and learning in new learning contexts (simulation, microworld, outdoor education) and approaches (problem-based learning, competency-based learning, etc.).

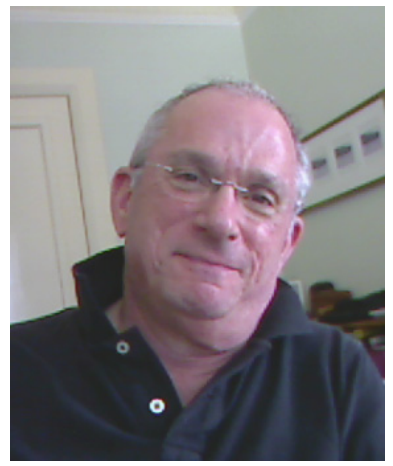

Harvey D. Feldstein is an internationally recognized author, speaker, and consultant in the areas of training, learning, and performance. Currently, Harvey is President and Managing Director of Baton Simulations, a worldwide organization devoted to helping organisations maximize the value of large ERP systems. For the past 30 years, he has been consulting with organizations and designing systems to help facilitate learning, transfer, and the accomplishment of worthy objectives. Formerly he was director and principal consultant at Appcon in Sydney, Australia, and Vice-President of Ziff-Davis Education in Rochester, NY (now Element-K). 


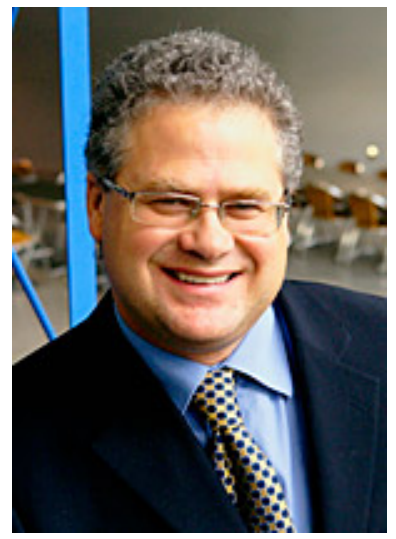

Dr. Jacques Robert is director of the Department of Information Technology at HEC Montréal. He holds a Ph.D. in economics from the University of Western Ontario. He is a Fellow at CIRANO where he served as vice-president responsible for the eBusiness Group. It is one of the co-inventors of the "HEC Montreal ERP Simulation Games" and chairman of Baton Simula-tions, the company which owns the commercial rights of ERPsim software.

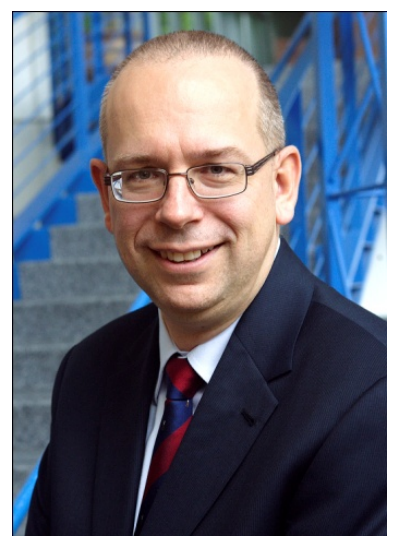

Dr. Gilbert Babin received his B.Sc. and M.Sc. from Université de Montréal (Canada) in 1986 and 1989, respectively. He then completed his Ph.D. in 1993 at Rensselaer Polytechnic Institute (Troy, New York, USA), which earned him the Del and Ruth Karger Dissertation Award in 1995. He worked at Université Laval from 1993 to 2000. Since then, he joined HEC Montréal (Canada) as Associate Professor. Gilbert Babin is a member of ACM and CS-IEEE. He has over 60 papers published in refereed journals and conferences. His research interests include distributed systems and their integration. He is one of the coinventors of ERPsim.

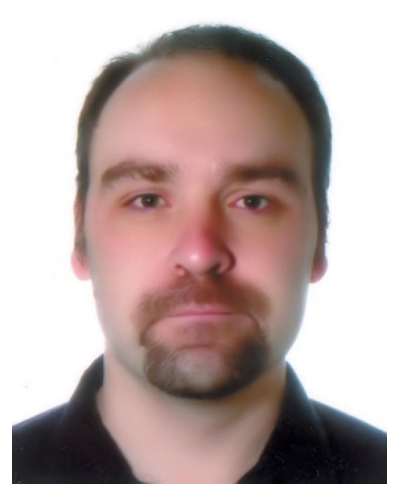

Derick Lyle is a part-time lecturer in Information Technology at HEC Montreal, and Chief Technology Officer of Baton Simulations. He has 15 years of commercial software development and project management experience in industries as diverse as agriculture to pharmaceuticals, in Australia, the United States and Europe. He received his Bachelor of Economics in 1994 from The University of Sydney (Sydney, Australia) and MBA in Technology Management in 2008 from HEC Montreal (Montreal, Quebec). 